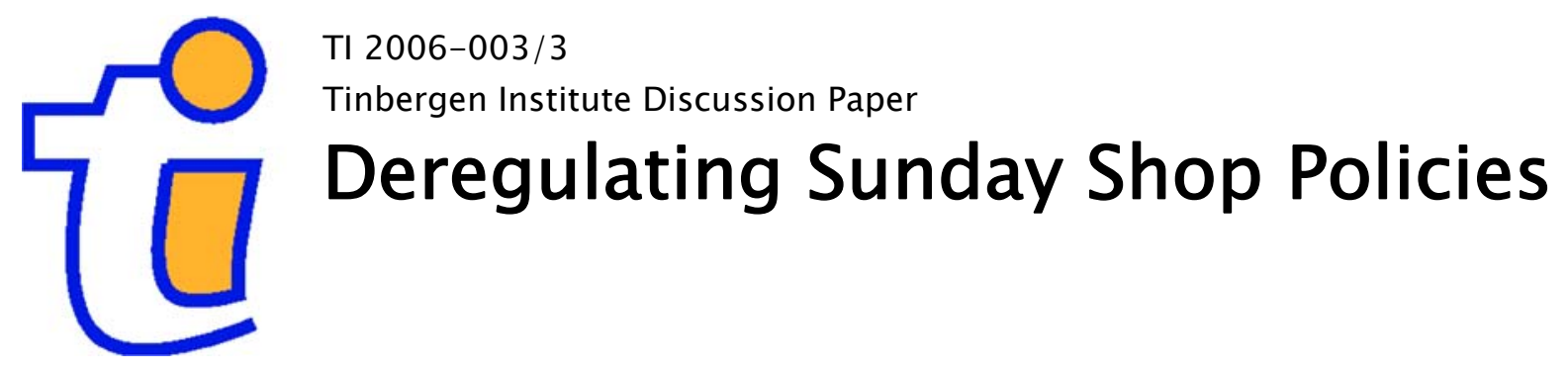

Elbert Dijkgraaf

Raymond Gradus ${ }^{2}$

' Erasmus University Rotterdam, and Tinbergen Institute;

2 Erasmus University Rotterdam. 


\section{Tinbergen Institute}

The Tinbergen Institute is the institute for economic research of the Erasmus Universiteit Rotterdam, Universiteit van Amsterdam, and Vrije Universiteit Amsterdam.

Tinbergen Institute Amsterdam

Roetersstraat 31

1018 WB Amsterdam

The Netherlands

Tel.: $\quad+31(0) 205513500$

Fax: $\quad+31(0) 205513555$

Tinbergen Institute Rotterdam

Burg. Oudlaan 50

3062 PA Rotterdam

The Netherlands

Tel.: $\quad+31(0) 104088900$

Fax: $\quad+31(0) 104089031$

Please send questions and/or remarks of nonscientific nature to driessen@tinbergen.nl.

Most TI discussion papers can be downloaded at http://www.tinbergen.nl. 


\title{
Deregulating Sunday Shop Policies
}

22 December 2005

\author{
E. Dijkgraaf \\ and \\ R.H.J.M. Gradus*
}

\begin{abstract}
Sunday shop opening is deregulated to the municipal level in the Netherlands. Despite positive effects on economic growth and employment, many municipalities restrict Sunday shop opening. Based on 2003 data we show that diverse local characteristics, like the size of municipalities and religious and political affiliation, play a major role in decisions about Sunday shop opening. The evidence is consistent with the hypothesis that municipal control over Sunday shopping hours results in a considerable variation in policies. As this variation is related to significant differences between municipalities, reasons exist to decentralize the decision on Sunday shopping opening.
\end{abstract}

Keywords: Sunday opening, economic regulation, decentralization.

Jel classification: D 78, L 51 


\section{Introduction}

In the last years European countries regularly debate about relaxing shop opening hours legislation. As an outcome of this debate some legal restrictions have been relaxed for example in Sweden, the Netherlands and Germany. Since 1972 in Sweden opening hours are unrestricted for all stores. Until June 1996 Dutch shops were not allowed to be open on evenings and on Sundays, today shops can be open from 6 to 22 hours and Sunday trading can be allowed 12 times a year (and on all Sundays in tourist regions). In Germany liberalization was decided in November 1996 changing closing time on weekdays from 18.30 to 20.00 and on Saturday from 14.00 to 16.00 hours.

From an economic point of view strong arguments exist for a less tight regulation of shop opening hours. The fast growing empirical literature about this issue stresses unequivocally out more employment and welfare gains for consumers. Burda (2000) and Gradus (1996) show that many European countries consider deregulation relevant for the policy debate concerning unemployment and job creation.

The economic literature points to substantial positive employment effects of longer opening hours, mainly due to an increase of threshold labour but possibly also as the result of increased sales as in Goos (2005), Gradus (1996) and Skuterud (2005). Moreover, liberalization results in markedly relaxed time constraints for consumers. The effect on prices is more doubtful. According to 
Nooteboom (1983) and CPB (1995) average prices may increase or decrease, dependent on the sum of higher costs due to increased threshold labour. On the other hand, Thurik (1984) reasons that an increase in productivity as a result of higher capital utilization may induce lower costs. Tanguay et al. (1995) suggests on the basis of evidence from the 1990 liberalization in Quebec that mark-ups may increase and that prices rise. However, this evidence is rather weak as it is based on short term effects only. The evidence from Sweden and the US suggests that prices fell (Burda and Weil, 2001).

Despite these positive economic effects most European countries still restrict opening on Sundays. In Germany, Norway and Switzerland opening is prohibited. Only in some countries, such as Ireland, Portugal, Sweden and the United Kingdom, there are (nearly) no legal restrictions. In Denmark and Finland restrictions apply only for large stores. These countries all have national regulation. In a few other countries, Belgium, Italy, Spain and the Netherlands, the decision is deregulated to the municipal or regional level. ${ }^{1}$ One reason for the high occurrence of restrictive Sunday opening laws might be that in the decision process not only effects on economic growth and employment play an important role, but also religious and social aspects. This is a general finding in the literature. Hersch et al. (2004), for instance, demonstrate that smoking regulation is the outcome of a complex interaction between economic arguments, interest group behavior and social preferences. Burda and Weil (2001) show that restrictions on Sunday trading are important 
if external effects of ruinous competition exist. In some European countries the regulation of Sunday shop opening hours is intended to reserve the Sunday as religious day for going to the church or pause day to rest. The restrictions in some US states on Sunday trading seem to have a religious background as well. Moreover, trade unions have supported restrictive policies from a social perspective.

Therefore, the decision process in most countries reflects an interesting trade-off. If markets value externalities like social implications and religious values improperly, regulation internalises these externalities. On the other hand this regulation reduces consumer choice and employment. Whether benefits are higher than costs, may depend on local circumstances. An important question is, therefore, which jurisdiction should make such a trade-off. Oates (1969) proves that welfare increases when the trade-off does take place at the level where externalities are valued homogenously. This means in our case that an important question is whether municipalities differ with respect to the values attached to Sunday shop opening externalities. If this is the case, the municipal level seems to be the appropriate jurisdiction from an economic point of view. The empirical literature presents only two studies that evaluate some of the reasons for liberal or restrictive shopping laws. Price and Yandle (1987) discuss for 25 US states the Sunday closing laws in 1970 and 1984. In 1970 they found evidence for a number of explaining variables for restrictive opening policies, including religious affiliation, political influence and the participation of women 
in the labour force. However, the 1984 results offer much less explanatory power. Ferris (1991) presents evidence for 45 Ontario cities. From the data it follows that higher female labour participation will decrease the probability of choosing early closing hours and that cities with a greater population density have more liberal laws. In this article weak evidence is found for religious affiliation, mostly because of data problems.

Therefore, the evidence on the reasons for Sunday opening laws are not very clear. The Dutch policy, deregulation of the decision on Sunday shop opening to the municipal level, provides a natural experiment that makes it possible to increase this evidence. Based on 2003 data for all (489) Dutch municipalities we analyse the determinants for differences in local shop opening regimes. We show that variation between municipalities depends on differences in interests of shop owners, social demand, ideology and regional circumstances. This indicates that the municipal level seems to be the appropriate jurisdiction to decide on shop opening from an economic point of view.

The remainder of this paper is organized as follows. Section II presents the methodology and section III describes the data. Section IV presents the estimation results. Section V gives some robustness tests and section VI concludes. 


\section{Methodology}

The basis for our analysis is the explanation of the decision Dutch municipalities made regarding the opening of shops on Sundays. As endogenous variable we have a variable $\left(\mathrm{SO}_{i}\right)$ describing the Sunday shop policy of municipality i. The main difference between municipalities is whether they allow Sunday openings or not. Therefore, our first specification is a binary probit model. ${ }^{2}$ In this model $\mathrm{SO}_{i}$ is zero for municipalities that do not allow open shops on any Sunday and one for municipalities with open shops on some Sundays. As an alternative we estimate an ordered probit model which measures the extent of shop opening days on Sundays. In this model $\mathrm{SO}_{i}$ takes the value one for municipalities which do not allow open shops on Sunday, ten for municipalities which allow open shops on all Sundays and values within one and ten for municipalities that allow open shops on some Sundays. In this last case the actual value depends on the number of Sundays for which shops are open (see section III and Appendix A). The reasons for the differences in local Sunday shop policies are analysed by regressing $\mathrm{SO}_{i}$ on a number of municipal characteristics. These characteristics are based on four theories, regarding the interests of shop owners, social demand, ideology and regional differences.

The first theory is based on the interests of shop owners. Some shop owners will advocate that shop opening on Sundays raise the attractiveness of shopping, especially in shopping centres with a richer diversity of shops or more 
specialized shops. People are more interested to shop in municipalities with a large number of shops. Thus, we include the number of shops per 1000 inhabitants $\left(\mathrm{SN}_{i}\right)$ to test whether municipalities with larger shopping possibilities have a more liberal Sunday shopping policy.

At the other side, especially small shop owners often experience difficulties when they expand opening hours due to the need to employ a certain 'threshold' labour at all times as in Nooteboom (1983). More restrictive regulation of opening hours tends to favour small stores. Furthermore, liberalizing shop opening hours regulation has the effect of lowering access cost and, according to Morrison and Newman (1983), the sales of large stores will increase. There is some evidence that local politicians often react to this unequal competition between small and large shops. This reaction will of course depend on the presence of small shops versus large shops. Therefore, we include the average number of employees per shop for each municipality $\left(\mathrm{SS}_{i}\right)$. Moreover, excessive shop opening hours in surrounding municipalities might generate competitive pressure. If customers can shop in surrounding municipalities, turnover turnover will diminish in municipalities with closed shops on Sunday. Ferris (1991) argues that retailers view shop hours as an effective instrument to appropriate customers from rivals. Kay and Morris (1987) show that competitive pressure may induce excessive opening at times when high costs would be incurred. We test this theory by including an impact factor measuring the extent of shop opening days in surrounding municipalities. 
This impact factor is calculated using the following equation:

$$
E N_{i}=\sum_{j} S O_{j}
$$

where $\mathrm{EN}_{i}$ is the impact factor of municipality $\mathrm{i}, \mathrm{i}$ is a vector of all municipalities, $\mathrm{j}$ is a vector of the municipalities with a liberal shop opening policy in the neighbourhood of municipality i. ${ }^{3}$

The second theory is based on the social demand for shop opening on Sundays. Jacobsen and Kooreman (2004) prove that the time spent on shopping on Sundays has increased significantly since the liberalization of Dutch opening hours. Thum and Weichenrieder (1997) argue that the possibilities to shop during the week will be less for couples that work both. They will value unrestricted shopping hours higher than single income families due to higher real (opportunity) cost of time during weekdays. We include the incidence of household with a double income $\left(\mathrm{HD}_{i}\right)$ to test this theory. A second household characteristic that might influence social demand for shop opening on Sundays is the size of the household. According to Eurostat (2003) parents of large households spent more time at home. We include the number of inhabitants per household $\left(\mathrm{HS}_{i}\right)$ to test whether large households value a more liberal policy higher.

Ferris (1991) argues that differences in population density across municipalities may influence the relative demand for Sunday opening. Customers in low 
population density areas will value distance higher than longer shopping times, increasing the possibilities for small shop owners to resist opening on Sundays. To test this theory, population density $\left(\mathrm{DE}_{i}\right)$ is included as well. The third theory is based on the ideological colour of the municipality. Posner (1974) made already clear that that voter ideology might influence the decision on shop opening hours. The Sunday opening decision of a municipality depends on voters' convictions. In the Netherlands orthodox protestant parties (SGP and CU) are strictly against Sunday shop opening. ${ }^{4}$ The larger Christian democratic party CDA is less strict as it accepts compromises far more easily. Based on the belief that the Sunday has a special Christian function local politicians of SGP, CU and (sometimes) CDA often try to keep the shops closed at Sundays. Other parties try to achieve the same goal from a social point of view. Left-wing parties like the SP (Socialist Party) and PvdA (Social Democrats) sometimes play together with Christian parties to reach a majority in the local political arena. Liberal parties like VVD (Conservative Liberals) and D66 (Left-wing Liberals) see Sunday shop opening as a good opportunity to enlarge the possibilities to shop and to stimulate the local economy. Because the Sunday opening decision is taken in the municipality council, the power of local political parties depends on the relative number of aldermen $\left(\mathrm{AL}_{i, p}\right) .^{5}$ However, the policy outcome does not only depend on the direct balance of power in the municipality council, but also on the influence of church members on the political parties. Although church and state are separated in the 
Netherlands, local church members often try to influence the policy debate. Therefore, municipalities with more active church members may show more restrictive Sunday policies. ${ }^{6}$ To test this effect we include the percentage of inhabitants that are active church members $\left(\mathrm{CH}_{i}\right) .^{7}$

As large cities in the Netherlands are ethnically heterogeneous societies with a diverse attitude towards Sundays, they will put more emphasis on a liberal policy. Moreover, as shopping on Sundays is used as a form of entertainment, larger municipalities have a better infrastructure for 'fun-shopping'. Ferris (1991), on the other hand, argues that a rise in the number of inhabitants diminishes the number of open Sundays. In this view, free-rider problems increase with the number of individuals due to coordination cost. To test the effect of municipality size we include the number of inhabitants $\left(\operatorname{IN}_{i}\right)$. Furthermore, to check for non-linearity the number of inhabitants squared is included as well.

The fourth theory is based on regional differences. Gradus (2001) finds some evidence that especially the provinces bordering Belgium (Brabant, Zeeland and Limburg) with their more Burgundian tradition have a more liberal Sunday shop policy. Another reason is the difference in excises between Belgium and the Netherlands. ${ }^{8}$ For example, according to Cnossen (2002) the excise on unleaded gasoline is $20 \%$ higher in the Netherlands. Furthermore, Sunday opening is allowed in Belgium for special stores as bakeries and furniture stores as well as for other stores in tourist municipalities, one can argue that 
cross-border shopping will speed up Sunday opening in these regions. Ferris (2000) proves that intense cross border shopping between the US and Canada was a major stimulus to deregulate the closing law in Ontario. This theory is tested by including a dummy for the provinces $\left(\mathrm{RE}_{i, k}\right)$ where Groningen is excluded as numeraire.

Table 1 summarizes the priors about the influence of variables representing the four theories on the probability of a less restrictive Sunday opening policy (see Appendix A for the exact definition of variables).

[Insert Table 1 here]

\section{Data}

Data for 282 Dutch municipalities on the incidence of shop opening on Sundays $\left(\mathrm{SO}_{i}\right)$ come from a website which gives information for the situation in 2003 (www.koopzondag.com). Data for the other 207 municipalities are gathered using website information of these municipalities, the results of an enquiry and direct contact with municipal representatives. We finally have data for all municipalities. There are no data available for years before 2003.

Table 2 shows how many municipalities allow for open shops on Sunday. ${ }^{9}$ Of all municipalities $32 \%$ have always closed shops on Sundays. The other extreme, all Sundays open shops, is allowed in $4 \%$ of the municipalities. In $66 \%$ of the municipalities Sunday opening is allowed in the range of only special Sundays 
like Boxing day (which is called second Christmas day in the Netherlands) to all Sundays. ${ }^{10}$

[Insert Table 2 here]

Data for the impact factor of neighbouring municipalities $\left(\mathrm{EN}_{i}\right)$ follow from the information on $\mathrm{SO}_{i}$ and the average distance between municipalities. Data for the other explaining variables are for 2003 and from the CBS (the Dutch

Central Bureau for Statistics). ${ }^{11}$ The variables are summarized in Table 3 (see Appendix A for a description of the variables).

[Insert Table 3 here]

\section{Results}

Table 4 presents the estimations results. The Andrews test statistic for goodness of fit of the binary probit model is significant at $99 \%$. The expectation-prediction table shows that the increase in correct predictions compared with the constant probability predictions is large for both values of $\mathrm{SO}_{i}$ : respectively $42 \%$ and $43 \%$. Both results indicate that the discussed theories do indeed explain a significant part of the variation between municipalities.

[Insert Table 4 here] 
The theory regarding interests of shop owners explains part of the differences in shop policies. Municipalities with a larger number of shops have a higher probability of a more liberal Sunday policy. The coefficient for the number of shops is significant and positive in both the binary and ordered probit. In the binary probit competitive pressure of neighbouring municipalities results in a lower probability of closed shops on all Sundays. In the ordered probit estimation this relation is not found. Apparently, the competitive pressure seems to have more influence in the decision to allow open shops or not and less in the decision how much Sundays shops may open their doors. Estimations with other values for the maximum distance defining neighbouring municipalities (10, 15 or 50 kilometres) show that for the binary probit estimations this variable is not always significant either. Thus, we conclude that there is only weak evidence for the influence of competitive pressure. The results for interests of small shop owners, i.e. size of shops, are more robust and in accordance with the 1970 results presented by Price and Yandle (1987). Both estimations show a significant and positive relation between the average number of employees per shop and the number of open Sundays.

The results for the household size and the number of households with double income show that differences in social demand explain part of the variation in shop policies. Municipalities with larger families and less households with a double income have a higher probability to have more restrictive Sunday policies. This is similar to Ferris (1991) and Price and Yandle (1987), where 
higher female participation stimulates Sunday opening. This result is also in accordance with the theoretical result by Thum (1997). The population density variable is not significant suggesting that Sunday opening is not more likely in a sparsely inhabited area. This result is contrary to Ferris (1991). A possible explanation is that the variation in the Netherlands is far less pronounced than in Canada.

The results for ideology are quite clear and stronger compared with Ferris (1991) and Price and Yandle (1987). Municipalities with more orthodox protestant (SGP and CU) aldermen show a much larger probability to have conservative policies. ${ }^{12}$ Interestingly, the CDA-variable is insignificant. Although the Christian Democratic Party has a historical foundation in Christian religion, the influence on Sunday shop opening is apparently not present. Evidence exist that some non-Christian parties might also stimulate a restrictive policy. The variables for PvdA (in the binary estimation) and for SP (in the ordered probit) show that social considerations might play a decisive role in the policy debate. ${ }^{13}$ The liberal philosophy of D66 cannot explain the significant negative coefficient for this party. However, there is no significance in the ordered probit. The second variable measuring the influence of ideology, the incidence of active church members, is significant in both estimations. Municipalities with more active church member citizens have more stringent Sunday policies. ${ }^{14}$ 
The coefficient of inhabitants squared in the binary probit estimation makes clear that the positive effect of the number of customers diminishes. As the cultural diversity of large cities is much larger than for small municipalities, a threshold effect can be assumed in the choice between zero or some open Sundays. ${ }^{15}$ At first sight this result is contrary to that of Ferris (1991). Based on data for 45 large and medium-sized cities in Ontario he finds a positive but insignificant relationship between size and Sunday opening. Our results indicate, however, that size does only matter if small and large municipalities are included. Therefore, our results may in fact be in accordance with those found by Ferris (1991). Indeed, if we exclude the 75 municipalities which have less than 9,500 inhabitants the coefficient for inhabitants squared is no longer significant. This intuition corresponds with the insignificant coefficient of the squared variable in the ordered probit estimation.

The data show some evidence for the regional differences argument. In the ordered probit the coefficients for the provinces Brabant, Zeeland, Limburg and Overijssel are significant at 95\%, while the coefficients for Limburg and Zeeland are significant at $90 \%$ in the ordered probit. These regressions imply that there is some evidence that cross-border shopping is an important element for the opening hour's policy in municipalities especially adjacent to Belgium. This is in accordance with Ferris (2000) who found that after a period of intensive cross border shopping (due to a Canadian/US exchange rate that favoured US shopping), competition was a major stimulus in liberalizing Sunday shopping in Ontario. 
An interesting question is whether the estimation results give information about the relative weight of the variables. Calculation of the change in probabilities for the binary $\mathrm{SO}_{i}$ if the variables representing the theories are varied by one standard deviation reveals that ideology and regional culture play a larger role than the other theories. Especially the number of inhabitants, the presence of SGP, CU and D66-aldermen, the number of active church members and the regional culture influence the Sunday policy (see Table 5). ${ }^{16}$ For example, if the number of inhabitants increases with one standard deviation, the probability that a municipality allows Sunday opening increases with $22 \%$. Moreover, if the number of active church members increases from 13 to 18 per 100 inhabitants the probability decreases with $16 \%$.

[Insert Table 5 here]

\section{Robustness}

As multicollinearity may play a role we estimate also specifications excluding some of the variables to analyse whether standard errors are influenced. These estimations give no indication that multicollinearity influences our conclusions. Furthermore, none of the correlations between explaining variables exceeds 0.5 in absolute values. Even for variables where collinearity could be expected, like household size versus the percentage of active church members or population density, correlations are rather low. Apparently our dataset is large enough to 
make robust estimation of all included variables possible. Moreover, we tested also for heteroskedasticity. The LM test statistic is 1.53 for the binary probit, which is insignificant at all usual levels. Standard errors are therefore not corrected for heteroskedasticity.

As an alternative to the presented ordered probit model with ten categories, we estimate also a model with a less refined specification (five categories) of the $\mathrm{SO}_{i}$ variable to test for partial ordering. The results for this estimation are not significantly different from the refined version.

Some remarks are necessary about the endogeneity of the explaining variables. First, it is, for example, possible that the open shop policies are not only influenced by the number of shops (SN) or the size of shops (SS), but that these variables depend also on the shop policies itself. This is for instance the case if relaxation of shop policies stimulates economic development. To test this, we estimate a system of equations for SO, SN and SS (using Full Information Maximum Likelihood) to analyse whether shop policies influence SN and SS. Both coefficients for SO in the SN and SS specification, however, are insignificant. $^{17}$

Second, as the explaining variables refer to 2003, one could argue that some of them are not exogenous. To test for endogeneity problems we estimate with 1996 data for the variables where endogeneity might be present (SN, SS, HS, HD, DE and IN). ${ }^{18}$ On the basis of a Wald-test, most coefficients are not significantly different from our initial model (compare Table 4 and 6). However, 
household size (HS) is no longer significant in the binary estimation of the new model, while it is only significant at $10 \%$ in the ordered probit estimation. Nevertheless, HS is not a variable where endogeneity might be expected.

\section{[Insert Table 6 here]}

Furthermore, the impact factor for surrounding municipalities (EN) is no longer significant in the binary estimation. As it was already insignificant in the ordered probit, the conclusion is that the proof for the effect of surrounding shop policies is very weak. This could result from an endogeneity problem. In our estimations the variable that measures the impact of surrounding municipalities is treated exogenously (see equation II.1). If this variable is in fact jointly determined, the strategic behaviour of municipalities should be taken into account. The appropriate methodology would be to use spatial econometric techniques. The literature provides robust measures to test for spatial autocorrelation. Bivand and Szymanski (2000) for instance use Moran's I to show that for the UK spatial autocorrelation was present in the waste collection market before the introduction of compulsory competitive tendering. In our case Moran's I measures the correlation of the Sunday shop policy of municipalities with the policies of neighbours. Moran's I lies between -1 and 1 . If Moran's I is zero no spatial autocorrelation is present. Using software described in Ferstl (2004) we calculate Moran's I for different weighing schemes. ${ }^{19}$ Table 7 summarizes the results. Nearly all Moran's I's are 
insignificant. Only for large distances a significant result is found. However, in these cases Moran's I is very small and even negative. We conclude that spatial autocorrelation is not present.

\author{
[Insert Table 7 here]
}

\title{
VI Conclusions
}

Since 1996 the decision on Sunday shop opening is deregulated to the municipal level. They may allow for 12 open Sundays per year or even open shops on all Sundays when they are in a tourist region. Still, $32 \%$ of the Dutch municipalities shops are closed on every Sunday in 2003. Drawing on various theoretical arguments, two statistical (binary and ordered probit) models were estimated to explain the occurrence of restrictive Sunday opening. It is shown that especially the number of inhabitants, political affiliation, religious affiliation and regional differences are important to explain the variation between municipalities. The number and size of shops and household characteristics are significant as well, although their influence is smaller. There is very weak evidence for excessive competition with neighbouring municipalities, while cross-border shopping may play a role.

The evidence is consistent with the hypothesis that municipal control over Sunday shopping hours results in a considerable variation in policies. As this variation is related to significant differences between municipalities, 
deregulation to the local level allows municipalities to take account of local characteristics. Clearly, reasons exist to decentralize the decision on Sunday shopping opening from an economic point of view.

In this paper we only investigate the policy decision by the municipality. Less restrictive policies do not necessarily imply that all shops are in fact open at Sundays. There is some evidence that especially food and furniture stores make use of a more liberal policy. In large cities also shopping centres and special stores are open. Future research might generate more insight in the opening decision of show owners when data are available about the opening hours of individual shops. 


\section{References}

Barro, R.J. and R. McCleary. "Religion and Economic Growth.", NBER Working Paper 9682, 2003.

Bivand, R. and S. Szymanski. "Modelling the spatial impact of the introduction of Compulsory Competitive Tendering." Regional Science and Urban Economics, 30, 2000, 203-219.

Burda, M.C. "Product Market Regulation and Labour Market Outcomes: How Can Deregulation Create Jobs.", CESifo Working Paper no. 230, 2000.

Burda, M.C. and P. Weil. "Blue Laws.", paper presented at the SOLE Conference, 2001.

Cnossen, S. "Tax Policy in the European Union.", CESifo Working Paper Series 758, 2002.

CPB "Economische Effecten van Liberalisering van Winkeltijden in Nederland (Economic effects of shop liberalisation in the Netherlands).", Centraal Planbureau: Den Haag, 2005.

Eurostat "Time Use at Different Stages of Life.", Eurostat: Luxembourg, 2003.

Ferris, J.S. "On the Economics of Regulated Early Closing Hours: Some Evidence from Canada." Applied Economics, 23, 1991, 1393-1400. 
Ferris, J.S. "The Determinants of Cross Border Shopping: Implications for Tax Revenues and Institutional Change." National Tax Journal, 53, 2000, 801-824.

Ferstl, R. "Werkzeuge zur Analyse räumlicher Daten: eine Softwareimplementation in EViews und MATLAB.", Wirtschafsuniversität: Wien, 2004.

Goos, M. "The impact of shop closing hours on labour and product markets." London School of Economics, 2005.

Gradus, R.H.J.M. "The Economic Effects of Extending Shop Opening Hours." Journal of Economics, 64, 1996, 247-263.

Gradus, R.H.J.M. "Ethiek en Economie: de Zondagopening (Ethics and Economics: Sunday Opening of Shops).", in Economolgues: liber amicorum for Theo van de Klundert, edited by H. Klok et al., 2001, 159-171.

Hersch, J., A.F. Del Rossi and W.K. Viscusi. "Voter preferences and state regulation of smoking." Economic Inquiry, 42, 2004, 455-468.

Jacobsen, J.P. and P. Kooreman. "Timing Constraints and the Allocation of Time: The Effects of Changing Shopping Hours Regulations in The Netherlands." European Economic Review, 49, 2004, 9-27. 
Kay, J.A. and C.N. Morris. "The Economic Efficiency of Sunday Trading Restrictions." Journal of Industrial Economics, 36, 1987, 113-129.

Morrison, S.A. and R.J. Newman. "Hours of Operation Restrictions and Competition among Retail Stores." Economic Inquiry, 21, 1983, 107-114.

Nooteboom, B. "Trading Hours and Economy of Scale in Retailing." European Small Business Review, 1, 1983, 57-62.

Oates, W.E. "The effects of property taxes and local public spending on property values: An empirical test of tax capitalization and the Tiebout hypothesis." Journal of Political Economy, 77, 1969, 957-970.

OECD "Regulation and Performance in the Distribution Sector.", Economics Department, working paper 180, 1997.

Posner, R. "Theories of Economic Regulation." Bell Journal of Economics and Management, 5, 1974, 335-338.

Price, J. and B. Yandle. "Labour Markets and Sunday Closing Laws." Journal of Labor Research, 8, 1987, 407-414.

Skuterud, M. "The Impact of Sunday Shopping Deregulation on Employment and Hours of Work in the Retail Industry: Evidence from Canada." European Economic Review, 49, 2005, 1953-1978.

Tanguay, G., L. Vallee and P. Lanoie. "Shopping Hours and Price Levels in 
the Retailing Industry, A Theoretical and Empirical Analysis." Economic Inquiry, 33, 1995, 516-524.

Thum, M.P. and A. Weichenrieder. "'Dinkies' and Housewives, The Regulation of Shopping Hours." Kyklos, 50, 1997, 539-559.

Thurik, R. "Labour Productivity, Economies of Scale and Opening Time in Large Retail Establishments." The Services Industries Journal, 1, 1984, $19-29$. 


\section{Authors and acknowledgements}

* Elbert Dijkgraaf is corresponding author: SEOR-ECRi and Tinbergen

Institute (Erasmus University Rotterdam), Room H 7-34, P.O. Box 1738, 3000

DR Rotterdam, The Netherlands, Tel: +31 10 4082590, Fax: +31 10 4089650,

Email: dijkgraaf@few.eur.nl.

Raymond Gradus is affiliated to the Erasmus University Rotterdam (ECRi) and to the Vrije Universiteit Amsterdam, Tel: +3170 3334460, Fax: +3170 3334079, Email: Rgradus@minszw.nl.

We thank A.M.W. Wojcik and the CBS for providing some of the data and M. Goos, J.S. Ferris and B. Melenberg for comments on an earlier version.

\section{Notes}

${ }^{1}$ This information is based on OECD (1997) and an update using website information of the responsible authorities in different countries.

${ }^{2}$ As an alternative we estimate also a logit model. All results are very similar.

${ }^{3}$ Neighbourhood municipalities are defined as those municipalities that are 
no further away than 25 kilometres (17 miles). Alternative assumptions with different maximum distances are also tested. See section IV.

${ }^{4} \mathrm{On}$ a national scale these parties are small (each about $2 \%$ of total votes). However, the influence of these parties is large for some municipalities as the voters are regionally concentrated.

${ }^{5}$ Mayor and aldermen form the executive board. The mayor, whose executive power is limited, is appointed by the central government. The aldermen are elected by the municipal council. As a result of the proportional representation system only in a small minority of the municipalities one of the parties (most times CDA or PvdA) has a majority in the municipal council. In general, a coalition of parties has to be formed that governs the municipality for four years. Each coalition party has one or more aldermen, based on the size of the parties. The total number of aldermen depends on the number of inhabitants. As long as the coalition is stable, policies proposed by the aldermen will in general be accepted by the council.

${ }^{6} \mathrm{~A}$ different interpretation of the church attendance variable is that when the number of people going to church increases, the market size of Sunday shoppers decreases. This means that shop owners will have fewer incentives to open their shop on Sundays.

${ }^{7}$ In the Netherlands a large part of church members never attends church 
services. The included variable is related to members that attend church services at least once per week. The literature about the relation between religion and economics regularly finds different effects of religion and its intensity as in Barro and McCleary (2003). In our case variables representing church membership are not significant.

${ }^{8}$ In both countries excises and value-added taxes are set on a national level.

${ }^{9}$ The categories two till five presented in Table 2 are further divided in two subcategories in the ordered probit model, based on an opening regime for part of or the whole municipality (see Appendix A).

${ }^{10}$ Note that we use the term Sundays also for days like Easter Monday. Traditionally shops were not open on Sundays and special days like Easter Monday, Whit Monday and Boxing Day. Currently, most municipalities may open shops on 12 Sundays and special days, except for Christmas day, Easter Sunday and Whit Sunday. Municipalities in tourist regions may open shops on all Sundays.

${ }^{11}$ All variables are available per municipality, except for the active church member variable. This variable is available for 42 regions. In section VI we discuss the use of explaining variables from the same year as for $\mathrm{SO}_{i}$.

${ }^{12}$ Note that the coefficients for SGP and CU are significantly different from each other in the ordered probit, but not in the binary case. This is not surprizing as the SGP is the most conservative protestant party. 
${ }^{13}$ Note that the coefficient for PvdA does not differ significantly from the coefficients of SGP and CU in the binary case. However, the coefficients of SGP and SP do differ in the ordered probit case.

${ }^{14}$ Interestingly, variables representing the incidence of church members that are less active (in terms of the number of times they attend services) are not significant. Results are available upon request.

${ }^{15}$ According to our estimates the impact of size diminishes even when municipalities have more than 410,0000 inhabitants. However, as only three municipalities have this size, this decrease is in fact an out of sample result. A Wald-test of the first derivative with respect to municipality size shows that the size effect is significantly different from zero (at 99\%) indeed.

${ }^{16}$ These figures are calculated using the average for all variables and varying significant variables with one standard deviation.

${ }^{17}$ These estimation results are available upon request.

${ }^{18}$ We do not have data before 1996 . However, it is not reasonable to assume that already in 1996 significant effects result from changes in Sunday shop opening in the second part of 1996 as all variables require considerable time to change. Note furthermore that we do not use the results with the 1996 data in the former paragraph as we have less data for 1996 (448 instead of 489). 
${ }^{19}$ We start by including all municipalities with open shops on Sundays and calculate the weights as the inverse of the distance between municipalities. In alternative analyses we set the weight for municipalities with open shops on Sundays at a larger distance than respectively 50, 37.5, 25, 15, 10 and 7.5 kilometres at zero. 


\section{Tables}

Table 1: Variables representing the theories

\begin{tabular}{lll}
\hline Theory & Representing variable & $\mathrm{p}\left(\mathrm{SO}_{i}\right)^{a}$ \\
\hline Interests shop owners & Number of shops (SN) & Positive \\
& Size of shops (SS) & Positive \\
& Policy surrounding municip. (EN) & Positive \\
Social demand & Size of households (HS) & Negative \\
& Double income households (HD) & Positive \\
& Population density (DE) & Positive \\
Ideological colour & Aldermen (AL) & Varying \\
& Active church members (CH) & Negative \\
& Inhabitants (IN) & Positive \\
Regional differences & Provinces (RE) & Varying \\
\hline
\end{tabular}

a. Probability of less restrictive Sunday opening policy.

Table 2: Sunday opening in Dutch municipalities

\begin{tabular}{lrr}
\hline Sunday policy (SO) & Municipalities & \% of total \\
\hline 1. Zero Sundays open & 155 & 32 \\
2. Only special days (max 5) like Boxing day & 18 & 4 \\
3. Less than 12 Sundays per year & 129 & 26 \\
4. 12 Sundays per year & 96 & 20 \\
5. more than 12, less than all per year & 70 & 14 \\
6. all Sundays per year & 21 & 4 \\
\hline
\end{tabular}


Table 3: Descriptive statistics

\begin{tabular}{lrrrr}
\hline & Average & Max & Min & St.dev. \\
\hline Number of shops per 1000 inhabitants (SN) & 6 & 18 & 0 & 2 \\
Size of shops in employees per shop (SS) & 5 & 15 & 2 & 2 \\
Impact factor surrounding municip. (EN) & 11 & 32 & 0 & 8 \\
Size of households (HS) & 2.5 & 3.6 & 1.8 & 0.2 \\
Double income households per 100 inh. (HD) & 16 & 21 & 10 & 2 \\
Population density (DE) & 5 & 255 & 0 & 16 \\
Aldermen as \% of total aldermen (AL) & & & & \\
- SGP & 2 & 50 & 0 & 8 \\
- CU & 3 & 50 & 0 & 9 \\
- CDA & 30 & 100 & 0 & 18 \\
- SP & 1 & 60 & 0 & 5 \\
- PvdA & 17 & 67 & 0 & 18 \\
- GL & 2 & 50 & 0 & 7 \\
- VVD & 16 & 67 & 0 & 18 \\
- D66 & 2 & 33 & 0 & 6 \\
Active church members as \% of inh. (CH) & 13 & 28 & 5 & 5 \\
Inhabitants (IN) & 33114 & 736562 & 1000 & 55660 \\
Province (RE) & & & & \\
- Groningen & 5 & 100 & 0 & 22 \\
- Friesland & 6 & 100 & 0 & 24 \\
- Drenthe & 2 & 100 & 0 & 15 \\
- Overijssel & 5 & 100 & 0 & 22 \\
- Flevoland & 1 & 100 & 0 & 11 \\
- Gelderland & 15 & 100 & 0 & 35 \\
- Utrecht & 7 & 100 & 0 & 25 \\
- Noord-Holland & 13 & 100 & 0 & 34 \\
- Zuid-Holland & 19 & 100 & 0 & 39 \\
- Zeeland & 3 & 100 & 0 & 16 \\
- Noord-Brabant & 14 & 100 & 0 & 35 \\
- Limburg & 10 & 100 & 0 & 30 \\
\hline & & & &
\end{tabular}


Table 4: Estimation results Sunday opening

\begin{tabular}{|c|c|c|c|c|}
\hline & \multicolumn{2}{|c|}{ Binary probit } & \multicolumn{2}{|c|}{ Ordered probit } \\
\hline Number of shops (SN) & $1.52^{* * *}$ & $(0.46)$ & $1.27^{* * *}$ & $(0.34)$ \\
\hline Size of shops (SS) & $0.14^{* * *}$ & $(0.05)$ & $0.06^{*}$ & $(0.03)$ \\
\hline Impact factor surrounding municip. (EN) & $0.01^{*}$ & $(0.01)$ & 0.00 & $(0.00)$ \\
\hline Household size (HS) & $-0.97^{* *}$ & $(0.41)$ & $-1.07^{* * *}$ & $(0.41)$ \\
\hline Households with double income (HD) & $0.12^{* *}$ & $(0.05)$ & $0.09^{* *}$ & $(0.04)$ \\
\hline Population density (DE) & -1.63 & $(4.48)$ & 2.83 & $(3.44)$ \\
\hline Alderman (AL): & & & & \\
\hline - SGP & $-4.29 * * *$ & $(1.54)$ & $-5.91^{* * *}$ & $(1.42)$ \\
\hline$-\mathrm{CU}$ & $-1.95^{* *}$ & $(0.91)$ & $-1.79^{* *}$ & $(0.75)$ \\
\hline - CDA & -0.30 & $(0.47)$ & -0.03 & $(0.30)$ \\
\hline$-\mathrm{SP}$ & -2.48 & $(2.06)$ & $-1.94^{*}$ & $(1.04)$ \\
\hline - PvdA & $-0.70^{*}$ & $(0.44)$ & -0.42 & $(0.32)$ \\
\hline - GL & 1.49 & $(1.22)$ & -1.11 & $(0.74)$ \\
\hline - VVD & -0.13 & $(0.45)$ & -0.22 & $(0.31)$ \\
\hline - D66 & $-2.56^{* *}$ & $(1.20)$ & -0.98 & $(0.82)$ \\
\hline Active church members $(\mathrm{CH})$ & $-0.09^{* * *}$ & $(0.03)$ & $-0.08^{* * *}$ & $(0.02)$ \\
\hline Inhabitants (IN) & $2.79^{* * *}$ & $(0.74)$ & $0.94^{* * *}$ & $(0.30)$ \\
\hline Inhabitants squared $\left(\mathrm{IN}^{2}\right)$ & $-0.34^{* * *}$ & $(0.13)$ & -0.05 & $(0.07)$ \\
\hline Province (RE) & & & & \\
\hline - Friesland & 0.27 & $(0.42)$ & 0.16 & $(0.34)$ \\
\hline - Drenthe & 0.17 & $(0.54)$ & 0.26 & $(0.40)$ \\
\hline - Overijssel & 0.77 & $(0.50)$ & $0.88^{* *}$ & $(0.36)$ \\
\hline - Flevoland & 0.46 & $(0.87)$ & $0.91^{*}$ & $(0.55)$ \\
\hline - Gelderland & 0.00 & $(0.39)$ & $0.55^{*}$ & $(0.30)$ \\
\hline - Utrecht & -0.63 & $(0.46)$ & 0.12 & $(0.35)$ \\
\hline - Noord-Holland & -0.50 & $(0.43)$ & 0.32 & $(0.32)$ \\
\hline - Zuid-Holland & -0.39 & $(0.43)$ & 0.49 & $(0.32)$ \\
\hline - Zeeland & $1.19^{*}$ & $(0.64)$ & $2.48^{* * *}$ & $(0.45)$ \\
\hline - Noord-Brabant & 0.76 & $(0.49)$ & $0.79^{* *}$ & $(0.33)$ \\
\hline - Limburg & $0.90^{*}$ & $(0.51)$ & $1.17^{* * *}$ & $(0.34)$ \\
\hline Log likelihood & -187.01 & & -833.95 & \\
\hline
\end{tabular}

Notes: Standard errors are given in parentheses. All coefficients are insignificant except for coefficients with $* / * * / ;^{* * *}$ which denotes significant at the $90 / 95 / 99 \%$ level. 
Table 5: Effect on probability of less restrictive Sunday policy

\begin{tabular}{llr}
\hline Theory & Representing variable & $\mathrm{p}\left(\mathrm{SO}_{i}\right)^{a}$ \\
\hline Interests (small) shops & Number of shops (SN) & 0.08 \\
& Size of shops (SS) & 0.08 \\
& Policy surrounding municip. (EN) & 0.07 \\
Social demand & Size of households (HS) & -0.07 \\
& Double income households (HD) & 0.06 \\
Ideological colour & Population density (DE) & -0.01 \\
& Aldermen (AL: SGP, CU and D66) & -0.28 \\
& Active church members (CH) & -0.16 \\
Regional differences & Inhabitants (IN) & 0.22 \\
\hline
\end{tabular}

a. Probability of less restrictive Sunday opening policy. 
Table 6: Estimation results Sunday opening with 1996 data

\begin{tabular}{|c|c|c|c|c|}
\hline & \multicolumn{2}{|c|}{ Binary probit } & \multicolumn{2}{|c|}{ Ordered probit } \\
\hline Number of shops (SN96) & $1.15^{* *}$ & $(0.45)$ & $0.82^{* *}$ & $(0.32)$ \\
\hline Size of shops (SS96) & $0.14^{* * *}$ & $(0.05)$ & $0.09^{* * *}$ & $(0.03)$ \\
\hline Impact factor surrounding municip. (EN) & 0.01 & $(0.01)$ & 0.00 & $(0.00)$ \\
\hline Household size (HS96) & -0.38 & $(0.25)$ & $-0.69^{*}$ & $(0.37)$ \\
\hline Households with double income (HD96) & $0.05^{* *}$ & $(0.02)$ & $0.02^{* *}$ & $(0.01)$ \\
\hline Population density (DE96) & 0.43 & $(4.46)$ & 3.90 & $(3.25)$ \\
\hline \multicolumn{5}{|l|}{ Alderman (AL): } \\
\hline - SGP & $-5.08^{* * *}$ & $(1.70)$ & $-6.65^{* * *}$ & $(1.49)$ \\
\hline$-\mathrm{CU}$ & $-2.53^{* * *}$ & $(0.92)$ & $-2.11^{* * *}$ & $(0.75)$ \\
\hline - CDA & -0.39 & $(0.49)$ & -0.14 & $(0.32)$ \\
\hline - SP & -2.03 & $(2.17)$ & $-1.77^{*}$ & $(1.04)$ \\
\hline - PvdA & $-0.63^{*}$ & $(0.45)$ & -0.37 & $(0.33)$ \\
\hline - GL & 1.29 & $(1.21)$ & -0.99 & $(0.75)$ \\
\hline - VVD & -0.23 & $(0.47)$ & -0.28 & $(0.33)$ \\
\hline - D66 & $-2.43^{* *}$ & $(1.22)$ & -1.08 & $(0.84)$ \\
\hline Active church members $(\mathrm{CH})$ & $-0.09^{* * *}$ & $(0.03)$ & $-0.08^{* * *}$ & $(0.02)$ \\
\hline Inhabitants (IN96) & $3.44^{* * *}$ & $(0.83)$ & $0.92^{* * *}$ & $(0.32)$ \\
\hline Inhabitants squared (IN96 $\left.{ }^{2}\right)$ & $-0.44^{* * *}$ & $(0.14)$ & -0.05 & $(0.08)$ \\
\hline \multicolumn{5}{|l|}{ Province (RE) } \\
\hline - Friesland & 0.23 & $(0.42)$ & 0.17 & $(0.34)$ \\
\hline - Drenthe & 7.31 & $(100.10)$ & 0.60 & $(0.53)$ \\
\hline - Overijssel & 0.85 & $(0.54)$ & $0.95^{* *}$ & $(0.38)$ \\
\hline - Flevoland & 0.47 & $(0.93)$ & $0.97^{*}$ & $(0.55)$ \\
\hline - Gelderland & -0.13 & $(0.39)$ & $0.52^{*}$ & $(0.30)$ \\
\hline - Utrecht & -0.65 & $(0.47)$ & 0.19 & $(0.35)$ \\
\hline - Noord-Holland & -0.53 & $(0.44)$ & 0.40 & $(0.33)$ \\
\hline - Zuid-Holland & -0.45 & $(0.44)$ & 0.43 & $(0.33)$ \\
\hline - Zeeland & $1.52^{*}$ & $(0.81)$ & $2.71^{* * *}$ & $(0.49)$ \\
\hline - Noord-Brabant & 0.69 & $(0.52)$ & $0.85^{* *}$ & $(0.34)$ \\
\hline - Limburg & $0.84^{*}$ & $(0.51)$ & $1.28^{* * *}$ & $(0.35)$ \\
\hline Log likelihood & -170.17 & & -766.70 & \\
\hline
\end{tabular}

Notes: Standard errors are given in parentheses. All coefficients are insignificant except for coefficients with */**/;** which denotes significant at the 90/95/99\% level. 
Table 7: Moran's I

\begin{tabular}{lllll}
\hline Municipalities included & \multicolumn{2}{c}{ Binary } & probit & \multicolumn{2}{c}{ Ordered probit } \\
\hline All municipalities & -0.023 & $(0.009)^{* * *}$ & -0.013 & $(0.009)$ \\
- within distance of $50 \mathrm{~km}$ & -0.011 & $(0.002)^{* * *}$ & -0.009 & $(0.002)^{* * *}$ \\
- within distance of $37.5 \mathrm{~km}$ & -0.017 & $(0.012)$ & -0.013 & $(0.012)$ \\
- within distance of $25 \mathrm{~km}$ & -0.018 & $(0.020)$ & -0.010 & $(0.020)$ \\
- within distance of $15 \mathrm{~km}$ & -0.046 & $(0.036)$ & -0.014 & $(0.036)$ \\
- within distance of $10 \mathrm{~km}$ & -0.060 & $(0.068)$ & 0.054 & $(0.068)$ \\
- within distance of $7.5 \mathrm{~km}$ & -0.046 & $(0.107)$ & 0.145 & $(0.107)$ \\
\hline
\end{tabular}

Notes: Standard errors are given in parentheses. All coefficients are insignificant except for coefficients with $* / * * / ;^{* * *}$ which denotes significant at the $90 / 95 / 99 \%$ level. 


\section{Appendix A. List of variables}

SO Sunday shop policy of municipality i

- binary $\quad$ Value $=0$ for municipalities which allow no sunday opening

Value $=1$ for municipalities which allow sunday opening

- ordered Municipalities which allow sunday opening:

- never: value $=1$

- only on special days (like Easter Monday): value $=2$

- less than 12 times per year (only part of municipality): value $=3$

- less than 12 times per year (for the whole municipality): value $=4$

- 12 times per year (only for part of the municipality): value $=5$

- 12 times per year (for the whole municipality): value $=6$

- more than 12 times per year during a specific part of the year: value $=7$

- between 12 and all times per year (for part of the municipality): value $=8$

- between 12 and all times per year (for the whole municipality): value $=9$

- all times per year: value $=10$

SN Number of retail shops per municipality (divided by inhabitants)

SS Size of shops (employees per shop for retail)

EN Impact factor measuring sunday policy in surrounding municipalities

DE Population density (hectares per 1000 inhabitants)

HS Number of households (divided by inhabitants)

HD Number of households with double income (divided by inhabitants) 
AL Number of alderman (divided by total aldermen per municipality) for

- SGP - Orthodox protestants

- CU - Orthodox protestants

- CDA - Christian democrats

- SP - Socialistic Party

- PvdA - Social Democrats

- GL - - Green left

- VVD - Conservative liberals

- D66 - Progressive liberals

IN Number of inhabitants per municipality (divided by 100,000)

$\mathrm{CH} \quad$ Number of inhabitants that attend church services at least once per week (divided by total inhabitants)

$\mathrm{RE} \quad$ Dummy with value 1 if municipalities is part of province (12 provinces) 